\title{
Prediction of appropriate ICD-therapy using infarct heterogeneity from CMR in patients with coronary artery disease
}

\author{
Robert Jablonowski ${ }^{1 *}$, Uzma Chaudhry $^{3}$, Henrik Engblom ${ }^{1}$, Håkan Arheden ${ }^{1}$, Einar Heiberg ${ }^{1,2}$, Rasmus Borgquist ${ }^{3}$, \\ Marcus Carlsson'
}

From 18th Annual SCMR Scientific Sessions

Nice, France. 4-7 February 2015

\section{Background}

The heterogeneous peri-infarction zone surrounding the core infarct with cardiac magnetic resonance imaging (CMR) late gadolinium enhancement (LGE) has been linked to all-cause mortality in patients with coronary artery disease. Previously, the heterogeneity of fibrotic areas has been analyzed by threshold algorithms. We hypothesized that the heterogeneous peri-infarction zone is related to appropriate ICD-therapy in ischemic cardiomyopathy patients. Therefore, the purpose of this study was to investigate if 1 ) infarct heterogeneity can predict appropriate ICD-therapy and 2) evaluate which analysis method best depicts and quantifies the periinfarction zone.

\section{Methods}

Ischemic cardiomyopathy patients with a primary prophylactic ICD who underwent CMR on a $1.5 \mathrm{~T}$ scanner prior to ICD implantation were retrospectively included and divided into two groups (i) patients with appropriate ICD-therapy (anti-tachy pacing, shock or both) and (ii) patients with no ICD-therapy. A newly developed semiautomatic quantitative algorithm was used to evaluate the peri-infarction zone. This method was compared against a previously used threshold method with the total scar area defined as signal intensity $(\mathrm{SI})>2 \mathrm{SD}$ from remote myocardium, infarct core as SI $>3 \mathrm{SD}$ from remote and the peri-infarction zone defined as SI between 2 and 3SD from remote (Figure 1). Differences with a $\mathrm{p}<0.05$ were considered statistically significant.

'Cardiac MR group Lund, Dept of Clinical Physiology, Lund University, Lund, Sweden

Full list of author information is available at the end of the article

\section{Results}

A total of 14 patients were included in the analysis, six patients with appropriate ICD-therapy (age $53 \pm 11$ years, $100 \%$ male, LV-EF $29 \pm 9 \%$ ) and eight patients with no ICD-therapy (age $55 \pm 14$ years, $100 \%$ male, LV-EF $26 \pm 4 \%)$. The total scar burden was similar between both groups with and without ICD-therapy $(49 \pm 13 \mathrm{~g}$ vs $45 \pm 8 \mathrm{~g}, \mathrm{p}=0.1$ ).

The mean peri-infarction zone normalized to the total scar using the semi-quantitative algorithm was larger in the group with appropriate therapy $(34 \pm 1 \%)$ compared to the group with no ICD-therapy $(30 \pm 1 \%, \mathrm{p}=0.03)$, Figure 2 . There was no difference between groups using the threshold algorithm for peri-infarction zone analysis $(11 \pm 2 \%$ with appropriate ICD-therapy vs $10 \pm 2 \%$ with no therapy, $\mathrm{p}=0.4)$. There was a significant difference in peri-infarction zone normalized for total scar between the semi-automatic and threshold algorithm for patients with appropriate therapy $(\mathrm{p}=0.002)$ and no therapy $(\mathrm{p}=0.0003)$.

\section{Conclusions}

The peri-infarction zone quantified on CMR using a semi-automatic algorithm was larger in patients with appropriate ICD-therapy compared to patients with no ICD-therapy. The use of a threshold algorithm did, however, not separate the groups. Accurate quantification and characterization of the peri-infarction zone could aid in the identification of patients with infarction and at risk of ventricular arrhythmias and help to improve patient selection for primary prevention with ICDtherapy. 

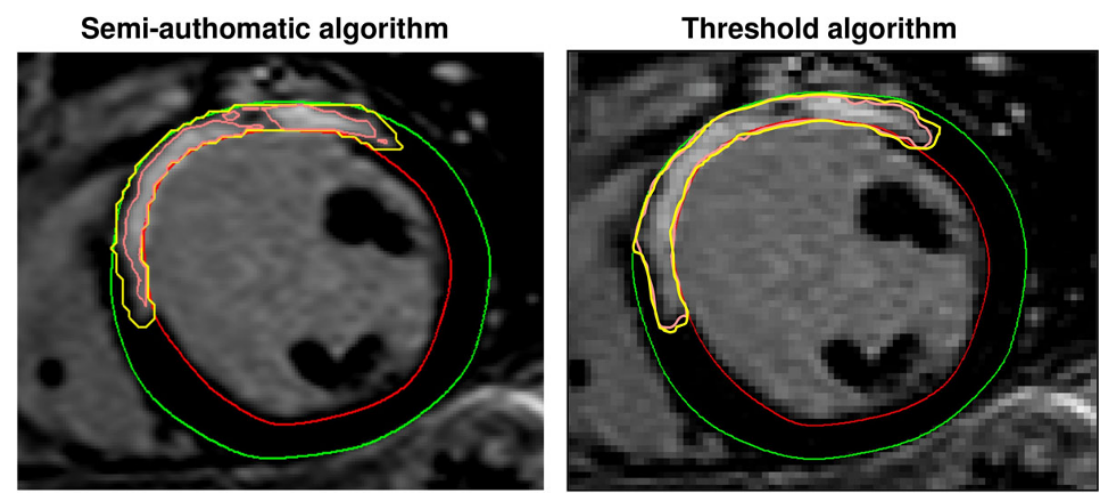

Figure 1 Representative short axis LGE-CMR images from one patient evaluated for peri-infarction zone with the semi-automatic algorithm (left panel) and threshold algorithm (right panel). The peri-infarction zone is defined as the area between the pink (infarct core) and yellow line. Red line=endocardium, green line=epicardium.

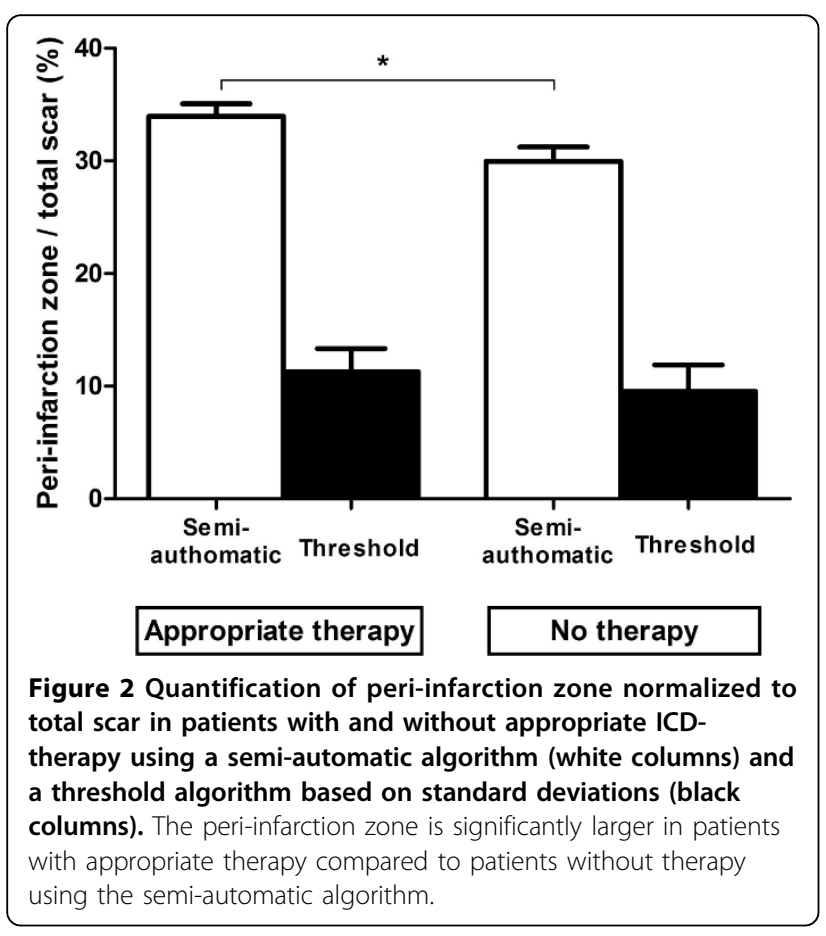

\section{Funding}

Lund University, Region of Scania.

\section{Authors' details}

${ }^{1}$ Cardiac MR group Lund, Dept of Clinical Physiology, Lund University, Lund, Sweden. ${ }^{2}$ Dept. of Biomedical Engineering, Faculty of Engineering, Lund University, Lund, Sweden. ${ }^{3}$ Dept. of Cardiology, Arrhytmia Clinic, Skane University Hospital, Lund University, Lund, Sweden.

Published: 3 February 2015
doi:10.1186/1532-429X-17-S1-P165

Cite this article as: Jablonowski et al:: Prediction of appropriate ICDtherapy using infarct heterogeneity from CMR in patients with coronary artery disease. Journal of Cardiovascular Magnetic Resonance 201517 (Suppl 1):P165.
Submit your next manuscript to BioMed Central and take full advantage of:

- Convenient online submission

- Thorough peer review

- No space constraints or color figure charges

- Immediate publication on acceptance

- Inclusion in PubMed, CAS, Scopus and Google Scholar

- Research which is freely available for redistribution 